\title{
"I know something about forces." Self-regulated learning during science investigations in a junior classroom
}

\author{
Chris Joyce and Rosemary Hipkins
}

$\mathrm{R}$ esearch on self-regulation of students' learning is seldom carried out at lower primary school levels. Fredricks,

Blumenfeld, and Paris (2004) identify gaps in current research knowledge about young school-age students' ability to self-regulate their learning. In particular they identify a lack of observational studies. One reason for these gaps, they suggest, is that it may be seen as developmentally inappropriate to look for self-regulation in young students because metacognitive (thinking about one's thinking) abilities are known to increase with age.

Zimmerman (2001) discusses self-regulated learning in terms of three clusters of factors:

- students' purposeful use of specific learning strategies;

- students' monitoring of the effectiveness of their learning; and

- a certain awareness of what motivates students to want to learn.

In this small study on young students and self-regulated learning, we (two researchers at the New Zealand Council for Educational Research) carried out an investigation to find out whether 5-to 7-year-olds could self-regulate, both with and without teacher support, and to explore what teacher actions might support them in developing self-regulated learning skills.

\section{Background to the investigation}

We worked with an experienced teacher of beginning school students at a small urban school. The class ranged from 5-yearolds (including one who started school the same day we began the series of lessons) to 7-year-olds. The teacher had already established an environment where student interactions and peer support were encouraged. When working independently, the students were in mixed-age groups of three.

To explore the students' ability to self-regulate their learning, we deliberately chose a complex context: that of carrying out fair tests about friction.

There were several parts to our investigation.

To begin, we observed two girls and two boys from the class working independently on a science investigation set by us. The science concept that underpinned the investigation was that what is inside a cylindrical container (we used a can) will influence the distance it will roll. This science idea was chosen because it is conceptually challenging, but the investigative skills required are relatively straightforward. We knew that "fair testing" of cans rolling down a ramp was something the students had been exposed to in their first year at school, but two cans of the same size, one with liquid contents and one with solid contents would, we thought, hold some surprises. Before beginning their investigation, there was a discussion about the focus of their learning-how forces acting on cans affect how far they roll. The students were provided with some instructions, a worksheet, and a range of materials, but there was little other intervention from us. We wanted to find out what self-regulated learning skills the students used spontaneously.

The focus of the next part of our research was to see what impact teacher actions and structured materials had on the students' ability to self-regulate. We worked with the teacher to plan four lessons to be taught on consecutive days. The sequence and the structure of the lessons, as well as the materials used, were aimed at supporting the students in developing both an understanding of the concept and the necessary investigation skills. The concept under investigation was frictional forces in the context of rolling. The teacher then taught the four sessions while we observed, capturing as many examples as we were able of students exhibiting aspects of self-regulation. After each session, we talked with the teacher about how the session had gone and together we made some adjustments for the next day.

Finally, we worked with the data from our observations to identify self-regulatory behaviours exhibited by the students and analyse what actions had prompted them.

\section{The planning}

When we were planning the four sessions (described briefly in Table 1) we took into account some research described by Fredricks et al. (2004). They identified several necessary factors before self-regulation was likely to occur. These included:

- a socially supportive and intellectually challenging environment; 
- creating conditions for positive peer interactions in which students "actively discuss ideas, debate points of view, and critique each other's work" (Fredricks et al., 2004, p. 77); and

- providing "complex hands-on tasks" combined with instructional support from a teacher who "presses students for understanding” (Fredricks et al., 2004, p. 79).

For each session, class discussion time was deliberately planned for before and/or after the practical activities. Harlen (2004) describes the importance of speech as reflection and argues that dialogue that is child centred "enables important goals of learning, for understanding and for learning how to learn, to be achieved" (p. 19). For most sessions there was some recording expected. Learning intentions were made clear for each session, and, importantly, the teacher kept referring back to these. Materials and strategies reduced the number of decisions students had to make about fair testing and supported group discussion. We designed questions that the teacher could use to keep the discussion focused.

\section{What we found out}

\section{The initial phase}

We found that these very young students were highly motivated to investigate. However, in the initial phase:

- they did not connect the action of investigating with the focus concept;

\section{TABLE 1. THE FOUR LESSONS}

Session 1: Free exploration

The students were given marbles and balls and asked to investigate how different surfaces affect rolling. Before they began, the students suggested different surfaces they could investigate, and at the end they discussed what they had found out.

\section{Session 2: Modelling}

The teacher and class worked together investigating the students' ideas from the previous day. The Predict, Observe, Explain (POE) strategy (Palmer, 1995) was used to elicit students' predictions about whether a marble would roll further on carpet or a smooth surface and their reasons for making this prediction. The teacher modelled how to think out loud about principles of fair testing and introduced a dot strategy for measuring.

\section{Session 3: Structured investigation}

The focus for this investigation was internal frictional forces. An initial activity looked at how water inside a dirty jar could clean the jar's internal surface when shaken. Students then investigated whether a jar of cotton wool or a jar of water rolled further. To help them think about how they would set up their investigation, they were initially asked to select from three cards of paired ramp settings (refer to Figure 1).

Session 4: Independent investigation

The students investigated whether a can of cat food or a can of soup would roll further. Discussion of a concept cartoon (Keogh \& Naylor, 1999) about the science concept supported them in making predictions (refer to Figure 2), but their investigations were carried out independently.

\section{Motivation and self-efficacy}

As with the first group, all of the class was engaged at a behavioural and motivational level. However, in contrast with the initial group, many of the class also began showing some instances of "minds on" behaviour. This was most often obvious during teacher-led discussion after the practical activities or when the prepared materials prompted them to think in this way. Fredricks et al. (2004) suggest that motivation at a cognitive level is a factor in becoming self-regulating.

\section{Awareness of learning strategies}

Students used learning strategies that had recently been modelled by the teacher. Older students, as leaders of their group, were likely to emulate the teacher. One girl in particular, Danielle, used the structured material to "be the teacher". She used the card pairs to coach the younger group members in making fair decisions and the concept cartoon to teach her group to consider what they thought about each statement. She also reminded her group to "remember what we found out yesterday". She was unable, however, to respond to answers she knew were incorrect, and once she began writing on behalf of the group in the recording book she no longer asked questions or included them in any way.

\section{Managing distractions}

\section{Maintaining a conceptual focus}

The teaching plan began with a relatively simple idea and unstructured exploration and gradually introduced more complex science ideas about friction and strategies for fair testing. With this support, we were surprised by the levels of complexity of some of the students' thinking.

One girl, Bea, when thinking about whether the can of cat food or soup would roll further (see Session 4), said, "The cat food is like the cotton wool and the soup is like the water" (identifying which was solid and which liquid). She then used the analogy to correctly predict that the can of cat food would roll further.

Brad, who had been at school for only 3 weeks, had an intuitive grasp of the interaction of variables. This requires sophisticated thinking. He discussed how both the surface on which the object was rolling and the surface of the object itself could affect the rolling distance and then also considered the size and weight of the object.

Having the students share their theories with the class during a teacher-led discussion 
was an important strategy for encouraging students to consider those complexities and to "think about their thinking". The role of the teacher in leading these discussions was a crucial factor in getting students to engage at both a cognitive and a metacognitive level, as was the willingness of most of the students to think aloud (not all of them did).

\section{Managing physical distractions}

A class of students rolling objects and sticking dots on the floor created a noisy and challenging environment in which to investigate. Gradually over the four teaching sessions, the students realised that they needed to create a space where their investigations were not affected by the actions of other groups. By the fourth day (and some before then), groups were thinking about where they would set up their investigations so their patterns of dots did not merge with other groups' patterns and where their rolling objects would not hit others' objects or the wall. Most students were able to attend to their own investigations and not be distracted by what was happening near them.

\section{Self-monitoring of fair testing strategies}

The structured materials and the teacher's modelling provided the students with support that allowed them to manage, for the most part, the variables of the investigation. Compared with the initial group, the students spent more time discussing the management of variables and keeping their investigations "fair". For example, the initial small group totally disregarded the fact that cans hit the wall when considering which rolled further. Yet one girl from this original group commented during the first teaching session, "They always hit something," and reorganised the group's equipment until this problem was overcome.

One boy displayed a clear understanding of variables. The students were asked to select (from a set of cards) the correct way to organise their equipment and then replicate it. The card he selected showed two ramps with carpet, but he chose two smooth ramps. When asked about this, he conceded that this was different from the card and then said, "But it doesn't matter, because they are still both the same."

\section{Drawing on previous experience}

In the second teaching session, the teacher modelled the use of coloured sticky dots to record the distances rolled. The visual patterns created when using this strategy make it possible to hold the variability of individual test runs in students' memory space while carrying out repeat runs in rapid succession (Hipkins \& Kenneally, 2003). The students enthusiastically picked up this strategy the next day. A 5-year-old from one group was heard to announce, "We need to get some dots." So in the short term students did independently use a strategy modelled by the teacher. However, if the use of this strategy is not practised in a number of contexts over a period of time, it seems likely that they will not retain it in the long term. The students in our initial group had used this strategy the year before, but not since. They did not remember it, even though we included boxes of dots in the materials we provided.

Class discussions offered an opportunity for students to talk about their theories and justify these in terms of previous experiences. For instance, one student talked at length about water affecting the slipperiness of marbles and how wet marbles would go further because of this. He knew about this, he told the class, because they had done this at kindergarten.

\section{Sustaining learning}

We looked for evidence that the students were continuing to investigate their own ideas separately from the formal teaching session. Because we were only in the classroom during the teaching time, it is possible that we missed examples of this. However, we did observe some instances. A boy who had just started school collected some small teddy bears and spent some time sliding them down a ramp. As this was done without any comment to anyone else, we have no way of knowing whether he was trying to find something out or whether it was just play. A more purposeful investigation was carried out by an older boy, who, towards the end of the last session, used two smooth ramps and compared the rolling of two jars of water. He then went looking for two different cans of cat food. Again, this was done alone, and he discussed neither his intentions nor what he found out with others.

A more overt example was when one of the boys introduced the word force during a discussion time. When the teacher asked him where he had learnt this word, he said he had seen it on the cover of the recording book. When he went home he had looked it up in the dictionary to find out what it meant. $\mathrm{He}$ was able to share a clear explanation of what a force was, and other students were then able to add to this. This prompted another student to make connections with what she knew: "I know something about forces. The magnet on the fridge forces the door to close."
These three examples demonstrate that at least some students in this class were sufficiently motivated to independently explore their own questions to further their learning.

\section{Making sense of our observations}

Zimmerman and Kitsantas (1997) wrote about a study involving high school students learning a skill. They identified four stages to acquiring a skill. These stages are:

- observation, where a skill is modelled so the learner gains an idea of what the skill looks like;

- imitation, when the learner emulates the model, often receiving feedback from the teacher;

- self-control, at which stage the learner no longer has to rely directly on the model but becomes proficient in the skill; and

- self-regulation, when the learner is able to adapt the skill to a changing environment. We used this work as a framework to organise the behaviours we observed during the teaching sessions. The four stages described by Zimmerman and Kitsantas also capture the emergent skills of self-regulated learning (refer to Table 2).

In contrast with the initial group, we observed many examples of emergent selfregulated behaviours during the four teaching sessions. Also obvious was the relationship between developing student autonomy and the support provided by the teacher and the learning materials. When the teacher was modelling, she was central to the action and the students mostly observed and emulated. However, as the teacher handed more control over to the students, we saw more examples of self-control (although the structured materials did provide support in students' decision making). Skilled questioning by the teacher helped the students to make the transition from imitation to self-control. The classroom environment, in which students were actively encouraged to work together and share their ideas, would also seem to provide support integral to the development of emergent selfregulation skills. Over the 4 days, the students were able to adapt what they had been doing with the teacher's support to allow them to work in independent groups carrying out a more cognitively challenging investigation.

\section{So what does this mean for teachers?}

We found that even young students can, with support, begin taking responsibility for their own learning. While it cannot be claimed that 
these 5-, 6-, and 7-year-olds were totally and independently self-regulating, many of them certainly took some responsibility for their learning.

We found instances of emergent selfregulated learning behaviour when the teacher provided a structure for students to learn and practise these behaviours. Actions that supported students were:

- pre-activity class discussion;

- post-activity class discussion;

- making the learning focus clear and referring back to this;

- modelling thinking out loud;

- teacher questioning;

- the teacher introducing and modelling the use of appropriate language;

- visual prompts (for example, cards to select which set of variables would be fair);

- simplifying the management of variables (for example, by providing pre-prepared equipment); and

- encouraging cognitive engagement by presenting alternative possibilities, using such strategies as concept cartoons (Keogh \& Naylor, 1999).
To summarise, we believe that the teacher in our study played a crucial role in developing foundations that will lead to the development of self-regulated learning. She modelled elements of self-regulation to the students, and she provided a social environment in which students could support one another when practising copying her behaviours. She kept returning to the purpose of the investigations to encourage students to think about what they were learning about friction, and she knew when to hand over to the students so they could start making decisions for themselves.

\section{Unhelpful strategies}

Two of the strategies we planned appeared to be unhelpful in encouraging students of this age to be self-regulating. One was asking the groups to reflect on their ideas in writing. The act of writing took so much effort, even for the 7-yearolds, that it overrode their ability to reflect on their learning or even to engage with others in the group. Students were more concerned with completing the task, spelling the words, and their handwriting than with reflection. This is in contrast with studies of older students,

TABLE 2. EXAMPLES OF EMERGENT SELF-REGULATED LEARNING BEHAVIOURS OBSERVED DURING THE EXPLORATORY PHASE

\begin{tabular}{|c|c|}
\hline STAGE & EXAMPLES OBSERVED \\
\hline Observation & $\begin{array}{ll}\text { - } & \text { Language modelled by teacher } \\
\text { - } & \text { Fair testing and measuring strategies modelled by teacher } \\
\text { - } & \text { Managing variables modelled by cards and paired equipment } \\
\text { - } & \text { Thinking aloud modelled by teacher } \\
\text { - } & \text { Thinking about theory modelled by concept cartoons }\end{array}$ \\
\hline Imitation & 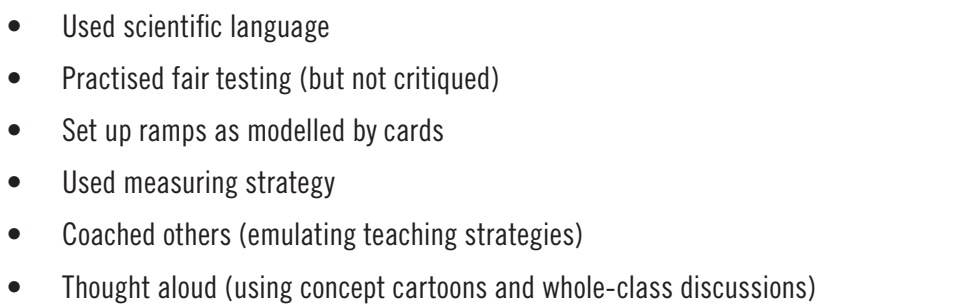 \\
\hline Self-control & $\begin{array}{l}\text { - Managed fair testing independently } \\
\text { - } \text { Drew conclusions from observations (both independently and supported by teacher } \\
\text { - } \text { questioning) } \\
\text { - } \quad \text { Drew on past experiences to justify ideas or predictions } \\
\text { - Managed physical distractions } \\
\text { - Debated ideas with teacher support }\end{array}$ \\
\hline Self-regulation & $\begin{array}{ll}\text { - } & \text { Critiqued own actions (when carrying out investigation) } \\
\text { - } & \text { Independently asked a question } \\
\text { - } & \text { Independently investigated to find out answers to own question }\end{array}$ \\
\hline
\end{tabular}

which indicate that writing does help the older students to reflect on their learning.

The second ineffective strategy was asking the students to reflect on their learning by choosing from a continuum of happy and sad faces. They were given a series of statements and asked whether they had used the described activity, for example, "We thought about the water in the jar," when they were thinking about the cans of cat food and soup. The younger students in the group did not engage in the task at all, and the older ones simply ticked all the smiliest faces. However, when they were asked to talk about the statements, they were able to share some quite sophisticated thinking about which learning episodes they had used effectively.

\section{Conclusion}

So what do we think self-regulated learning in the context of science investigations looks like in the first years of schooling?

- Firstly, we would see a role modelprimarily the teacher but sometimes another student-who demonstrates strategies to use, introduces the language that enables students to discuss their ideas, and talks out loud about their thinking. Further, students will be interacting with the role model and identifying and debating the key elements of the strategies in order to prepare to replicate these strategies.

- Secondly, students will be practising "doing what the teacher does". Initially, this will be within a structured task, initiated by or in partnership with the teacher, then as students learn the processes they will apply these in another context. Some students may begin using these processes independently to investigate questions they are interested in answering for themselves.

- Students will be sharing their ideas. They will be able to link these with things they have observed and/or experiences they have had. They will know why they are carrying out an investigation and will be able to use their investigations to inform personal theories.

- Some students may not be willing to talk about their ideas, but their actions may indicate that they are thinking about them (for example, extending a teacher-instigated investigation without comment).

- Students will manage physical distractions with either teacher support or the support of structured materials and begin to critique their management of variables.

- Most of their emergent skills will be supported by social interactions with others. 
At times, some students may step out of scenarios directed by the group to follow up on things they want to learn about and will use appropriate strategies to do so.

- Self-regulated learning skills are likely to be applied haphazardly and are influenced by the learning context, the environment, and the opportunities to learn that are instigated by the teacher.

Our small study provides some evidence that, even at a young age, students are able to begin developing skills of self-regulation in the context of science investigations. We found that teacher actions, the structure and sequence of lessons, structured materials, and social interactions were all influential in prompting students to monitor their skills in fair testing and to engage cognitively with the science concept under investigation.

\section{References}

Fredricks, J., Blumenfeld, P., \& Paris, A. (2004). School engagement: Potential of the concept, state of the evidence. Review of Educational Research, 74(1), 59-109.

Harlen, W. (2004). Talking and writing: Have we got the balance right? Primary Science Review, 8, 17-19.

Hipkins, R., \& Kenneally, N. (2003). Using NEMP to inform the teaching of scientific skills. Wellington: New Zealand Council for Educational Research.

Keogh, B., \& Naylor, S. (1999). Concept cartoons, teaching and learning in science:
Chris Joyce has responsibility for the overall development of the Assessment Resource Banks and assessment services at the New Zealand Council for Educational Research.

Email: chris.joyceळnzcer.org.nz

Rosemary Hipkins is a senior researcher with the New Zealand Council for Educational Research. Email: rosemary.hipkins@nzcer.org.nz
An evaluation. International Journal of Science Education, 21(4), 431-446.

Palmer, D. (1995). The POE in the primary school: An evaluation. Research in Science Education, 25(3), 323-332.

Zimmerman, B. (2001). Theories of self-regulated learning and academic achievement: An overview and analysis. In D. Schunk (Ed.), Self-regulated learning and academic achievement: Theoretical perspectives (2nd ed., pp. 1-37). New Jersey: Lawrence Erlbaum Associates.

Zimmerman, B., \& Kitsantas, A. (1997). Developmental phases in self-regulation: Shifting from process to outcome goals. Journal of Educational Psychology, 89(1), 29-36.

\section{Notes}

Some of the learning strategies used during this study have been developed as assessment resources. These can be accessed from the Assessment Resource Banks.

\begin{tabular}{|ll|}
\hline $\begin{array}{l}\text { Paired cards for } \\
\text { selecting a fair test }\end{array}$ & PW3688 and PW3690 \\
\hline Concept cartoon & PW3689 \\
\hline $\begin{array}{l}\text { Using sticky dots to } \\
\text { measure distance }\end{array}$ & \\
travelled & PW4110 \\
\hline
\end{tabular}

The full research paper can be accessed at http://www.nzcer.org.nz/pdfs/13891.pdf

\section{SHOP ONLINE A'T NZCER'S WEBSITE!}

Our website lets you shop online. It's a fast, easy, and secure way to order your books.

NOTE: Test ordering is not yet available online.

To shop on our site you need to register. Registration is easy and free. Just follow these simple instructions:

1. Go to www.nzcer.org.nz

2. Click on "My Account" (in the top right-hand corner of your screen).

3. In the "New Online Customer" box, click on the "Register Now" button.

4. Fill in your details. Remember to leave the "Options" on "Subscribe" to receive email updates on new publications and research findings.

5. Click "Continue" and you're registered!

6. Then follow the instructions "How to shop on this website". You might want to print them out to help with your first-time order.

Help: If you strike problems, contact sales@nzcer.org.nz

You can of course still order from NZCER Sales in the usual way:

Phone: $\quad 048021450$ or 048021451

Fax: $\quad 043847933$

Email: $\quad$ sales@nzcer.org.nz

The sales team, Joan and Sharon, look forward to providing you with even better service with online ordering. 